\title{
KUALITAS AIR IRIGASI DITINJAU DARI PARAMETER DHL, TDS, pH PADA LAHAN SAWAH DESA BULUMANIS KIDUL KECAMATAN MARGOYOSO
}

\section{IRRIGATION WATER QUALITY PARAMETERS BASED ON DHL, TDS, pH IN PADDY FIELDS OF BULUMANIS KIDUL VILLAGE MARGOYOSO SUBDISTRICT}

\author{
Arieyanti Dwi Astuti \\ Kantor Penelitian dan Pengembangan Kabupaten Pati \\ E-mail: ariey_antik@yahoo.com
}

Naskah Masuk: 14 Mei $2014 \quad$ Naskah Revisi: 21 Mei $2014 \quad$ Naskah Diterima: 30 Mei 2014

\begin{abstract}
As a source of irrigation water supplies, river plays an important role in influencing the quality of irrigation water. If the river water is used as irrigation water has been contaminated, it is directly or indirectly affect agricultural production. Suwatu River polluted waste of industrial tapioca is used as a source of water supply for irrigation of paddy fields in the Bulumanis Kidul village, Margoyoso Pati Regency. This study aims to determine the quality of irrigation water in paddy fields Bulumanis Kidul village in terms of physical parameters include Electrical Conductivity $(E C)$, Total Dissolved Solid (TDS) and the degree of acidity $(\mathrm{pH})$. This research is a descriptive case study method. Sources of data in the form are primary data from observations and laboratory testing. The results showed that the parameters EC and TDS still meet the quality standards, for $\mathrm{pH}$ parameters, there are two locations that do not meet the requirements according to the Government Regulation No. 82 /2001, for water class IV are location B and D.
\end{abstract}

Keywords: electrical conductivity, irrigation water, $\mathrm{pH}$, total dissolved solid

\begin{abstract}
ABSTRAK
Sebagai sumber pasokan air irigasi, sungai memegang peranan penting dalam mempengaruhi kualitas air irigasi. Apabila air sungai yang digunakan sebagai air irigasi telah tercemar, maka secara langsung maupun tidak langsung akan mempengaruhi hasil produksi pertanian. Sungai Suwatu yang tercemar limbah industri tapioka digunakan sebagai sumber pasokan air irigasi bagi lahan sawah di Desa Bulumanis Kidul, Margoyoso Pati. Penelitian ini bertujuan untuk mengetahui kualitas air irigasi pada lahan sawah Desa Bulumanis Kidul ditinjau dari parameter fisik yang meliputi Daya Hantar Listrik (DHL), padatan terlarut total (TDS) dan derajat keasaman ( $p H$ ). Penelitian ini merupakan penelitian deskriptif dengan metode studi kasus. Sumber data berupa data primer dari pengamatan dan pengujian laboratorium. Hasil penelitian menunjukkan bahwa parameter DHL dan TDS masih memenuhi baku mutu, sedangkan pada parameter $\mathrm{pH}$, terdapat 2 lokasi yang tidak memenuhi persyaratan menurut PP No. 82 Tahun 2001 untuk air kelas IV yaitu lokasi $B$ dan D.
\end{abstract}

Kata kunci: daya hantar listrik, air irigasi, pH, padatan terlarut total 


\section{PENDAHULUAN}

Air merupakan salah satu faktor yang sangat menentukan di bidang pertanian dalam penyediaan air irigasi. Sumber air permukaan sampai saat ini masih menjadi andalan dalam penyediaan air irigasi terutama pada musim kemarau. Namun sayangnya, dengan semakin meningkatnya pembangunan di segala bidang menyebabkan kuantitas dan kualitas air tidak lagi sesuai dengan peruntukannya. Pembangunan yang semakin meningkat diikuti dengan peningkatan pencemaran lingkungan, yang salah satunya berasal dari limbah industri.

Peningkatan pencemaran lingkungan sudah sejak lama terjadi di Kecamatan Margoyoso yang merupakan sentra industri tapioka. Pencemaran lingkungan ini diakibatkan oleh pembuangan limbah cair industri tapioka, salah satunya di Sungai Suwatu Margoyoso. Dampak negatif dari pencemaran sungai ini sudah banyak dirasakan masyarakat, terutama masyarakat di daerah hilir yang memanfaatkan sungai tersebut sebagai sumber pasokan air irigasi bagi pertanian dan pertambakan yang banyak terdapat di Desa Bulumanis Kidul.

Kualitas Sungai Suwatu tidak lagi sesuai dengan peruntukannya sebagai air irigasi pertanian bagi sawah di Desa Bulumanis Kidul. Hal ini diperkuat dengan penelitian Astuti (2012) yang menyatakan bahwa mutu air Sungai Suwatu memiliki nilai Indeks Pencemaran (IP) 11,19 pada bagian hilir yang termasuk dalam kategori tercemar berat. Salah satu kontributor terbesar dalam pencemaran tersebut adalah limbah cair industri tapioka yang dibuang pada Sungai Suwatu (Astuti dan Damayanti, 2012).

Apabila air sungai yang telah tercemar digunakan sebagai sumber pengairan lahan pertanian, maka ada akibat yang ditimbulkan secara langsung maupun tidak langsung yang akan mempengaruhi hasil produksi pertanian yang nantinya juga ikut mempengaruhi tingkat kesejahteraan masyarakat petani (Nooordwijk dkk, 2004). Hal ini sesuai dengan penelitian yang dilakukan Poniman (2004) yang menyatakan bahwa air yang mengandung limbah cair tapioka mampu menurunkan hasil Gabah Kering Giling (GKG) hingga $47,15 \%$. Lahan sawah yang dialiri limbah cair tapioka secara terusmenerus akan menurunkan sifat fisik, kimia dan biologis tanah. Berdasarkan uraian di atas maka penelitian ini bertujuan untuk mengetahui kualitas air irigasi pada lahan sawah Desa Bulumanis Kidul ditinjau dari parameter fisik menurut PP No. 82 Tahun 2001 yang meliputi Daya Hantar Listrik (DHL) atau Electrical Conductivity (EC), Padatan Terlarut Total atau Total Dissolved Solid (TDS) dan derajat keasaman $(\mathrm{pH})$.

\section{TINJAUAN PUSTAKA}

\section{Air Irigasi}

Pengelolaan air yang utama pada lahan sawah adalah irigasi. Secara umum, irigasi didefinisikan sebagai pemberian air untuk memenuhi kebutuhan air bagi tanaman. Pekerjaan irigasi meliputi menampung dan mengambil air dari sumbernya, mengalirkannya melalui saluran-saluran ke lahan pertanian dan membuang kelebihan air ke saluran pembuangan. Tujuan irigasi adalah untuk memberikan tambahan air (selain air hujan) dan memberikan air untuk tanaman dalam jumlah yang cukup pada saat dibutuhkan. Irigasi pada lahan sawah dimaksudkan untuk menjenuhkan tanah agar diperoleh struktur lumpur yang baik bagi pertumbuhan tanaman padi, memenuhi kebutuhan air tanaman, kebutuhan penggenangan dan mengganti kehilangan air di sepanjang saluran (Subagyono, 2004). Air irigasi juga harus ditilik dari mana sumbernya, sumber pengairan perlu diketahui untuk 
menentukan ada tidaknya cemaran serta mempelajari tingkat bahaya cemaran tersebut.

\section{Kualitas Air Irigasi}

Schwab dan Flevert dalam Noordwijk dkk (2004) membedakan sumber air irigasi menjadi 2 yaitu air permukaan (surface water) dan air bawah tanah (ground water). Air permukaan meliputi danau alami, waduk, dam dan sungai. Air permukaan dapat ditingkatkan ketersediaannya dengan memanen air hujan/aliran permukaan, sedangkan sumber air bawah tanah biasanya dimanfaatkan melalui pembuatan sumur dalam atau artesis (deep wells), mata air (springs) atau menggali/membuat kolam.

Sumber irigasi harus memenuhi syarat kualitas agar tidak berbahaya bagi tanaman yang akan dialiri, karena dalam jangka panjang dapat berpengaruh terhadap kualitas hasil produksi pertanian. Kualitas air merupakan faktor utama yang perlu dipertimbangkan dalam budidaya tanaman secara hidroponik. Tanaman terdiri atas $80-90 \%$ air sehingga ketersediaan air yang berkualitas sangat penting untuk mendukung keberhasilan proses budidayanya (Salisbury dan Ross dalam Susila dan Poerwanto, 2013). Kualitas air dapat ditentukan dari apa yang terkandung di dalam sumbernya (sumur atau sungai), juga tingkat kemasamannya.

\section{Daya Hantar Listrik (DHL)}

Kemampuan air sebagai penghantar listrik dipengaruhi oleh jumlah ion atau garam yang terlarut di dalam air. Semakin banyak garam yang terlarut semakin tinggi daya hantar listrik yang terjadi. DHL merupakan pengukuran tidak langsung terhadap konsentrasi garam yang dapat digunakan untuk menentukan secara umum kesesuaian air untuk budidaya tanaman dan untuk memonitor konsentrasi larutan hara. Pengukuran DHL dapat digunakan untuk mempertahankan target konsentrasi hara di zona perakaran yang merupakan alat untuk menentukan pemberian larutan hara kepada tanaman. Satuan pengukuran DHL adalah millimhos per centimeter $(\mathrm{mmhos} / \mathrm{cm})$, millisiemens per centimeter $(\mathrm{mS} / \mathrm{cm})$ atau microsiemens per centimeter (Susila dan Poerwanto, 2013). Berdasarkan nilai DHL dapat diketahui klasifikasi air irigasi seperti pada Tabel 1.

Tabel 1.

Klasifikasi Air Irigasi Berdasarkan Daya Hantar Listrik (DHL)

\begin{tabular}{ccl}
\hline $\begin{array}{c}\text { Kelas } \\
\text { Air }\end{array}$ & $\begin{array}{c}\text { DHL } \\
(\mu \mathrm{mhos} / \mathrm{cm})\end{array}$ & \multicolumn{1}{c}{ Keterangan } \\
\hline I & $0-250$ & Sangat Baik \\
II & $>250-750$ & Baik \\
III & $>750-2000$ & Agak Baik \\
IV & $>2000-3000$ & Kurang Baik \\
V & $>3000$ & Kurang Sesuai \\
\hline
\end{tabular}

Sumber: Colorado State University dalam Fitriyah (2012) 


\section{Total Dissolved Solid (TDS)}

Padatan terlarut total atau Total Dissolved Solid (TDS) adalah bahan-bahan terlarut (diameter $10^{-6} \mathrm{~mm}$ ) dan koloid (diameter $10^{-6} \mathrm{~mm}-10^{-3} \mathrm{~mm}$ ) yang berupa senyawa-senyawa kimia dan bahan-bahan lain yang tidak tersaring pada kertas saring berdiameter 0,45 $\mu \mathrm{m}$ (Rao dalam Effendi, 2003).

TDS biasanya disebabkan oleh bahan-bahan anorganik yang berupa ionion yang biasa ditemukan di perairan seperti air laut yang memiliki TDS tinggi. Hal ini terjadi karena adanya senyawa kimia yang banyak terdapat pada air laut yang juga mengakibatkan tingginya nilai salinitas dan konduktivitas atau Daya Hantar Listrik (DHL). Kandungan TDS pada air irigasi menurut PP No. 82 Tahun 2001 maksimal adalah 2000 mg/l untuk air kelas IV.

\section{Derajat Keasaman Air (pH air)}

Keasaman dan kebasaan dari air dinyatakan dalam $\mathrm{pH}$ dan diukur dalam skala 0 sampai 14. Angka yang semakin rendah menunjukkan kondisi larutan yang semakin masam, sebaliknya semakin tinggi pH maka kondisi larutan semakin alkalin. Skala pH adalah logaritmik, artinya peningkatan 1 angka, misalnya 4 ke 5 menunjukkan 10 kali peningkatan alkalinitasnya, demikian juga sebaliknya. Pengukuran $\mathrm{pH}$ mencerminkan reaksi kimia air dan larutan hara. Kondisi $\mathrm{pH}$ larutan hara sangat menentukan tingkat kelarutan unsur hara, dan ketersediaan hara bagi tanaman, dalam hal ini adalah air irigasi (Susila dan Perwanto, 2013). Kondisi pH optimum pada air irigasi (air kelas IV menurut PP No. 82 Tahun 2001) berkisar antara 6-9.

\section{METODE PENELITIAN}

Penelitian ini merupakan penelitian deskriptif menggunakan metode studi kasus. Dimana dalam penelitian ini menelaah secara mendalam suatu permasalahan pada waktu tertentu dan hasilnya belum tentu berlaku di daerah lain meskipun obyeknya sama (Hadi dalam Azwir, 2006).

Penelitian ini dilaksanakan pada bulan Juni-Agustus 2013 di lahan sawah yang menggunakan Sungai Suwatu sebagai sumber air irigasinya. Lokasi penelitian terletak di kawasan persawahan Blok Bacin yang berada di sebelah selatan Sungai Suwatu (Bulumanis Kidul, 2012).

Sampel untuk kualitas air irigasi diambil berdasarkan jarak dari sumber pencemar yang dalam hal ini adalah Sungai Suwatu. Sampel air yang diambil harus memenuhi kriteria antara lain: berada pada sawah yang masih digunakan sebagai budidaya pertanian, sawah menggunakan air Sungai Suwatu sebagai sumber irigasi, jarak terjauh dari Sungai Suwatu sekitar $200 \mathrm{~m}$, jika ada dua jarak dalam satu petak sawah maka cukup diambil salah satu saja sebagai sampel. Lokasi pengambilan sampel disajikan pada Tabel 2.

Tabel 2.

Lokasi Pengambilan Sampel

\begin{tabular}{cccc}
\hline Lokasi & $\begin{array}{c}\text { Lintang } \\
\text { (selatan) }\end{array}$ & $\begin{array}{c}\text { Bujur } \\
\text { (timur) }\end{array}$ & $\begin{array}{c}\text { Jarak dari Sungai } \\
\text { Suwatu (m) }\end{array}$ \\
\hline A & $6^{\circ} 36.737^{\prime}$ & $111^{\circ} 04.281^{\prime}$ & 57 \\
B & $6^{\circ} 36.742^{\prime}$ & $111^{\circ} 04.254^{\prime}$ & 91 \\
C & $6^{\circ} 36.760^{\prime}$ & $111^{\circ} 04.255^{\prime}$ & 123 \\
D & $6^{\circ} 36.804^{\prime}$ & $111^{\circ} 04.254^{\prime}$ & 202 \\
\hline
\end{tabular}

Sumber: Hasil Pengamatan (2013) 
Pada penelitian ini, parameter kualitas air irigasi yang diukur hanya berupa parameter fisik meliputi Daya Hantar Listrik (DHL), Total Dissolved Solid (TDS) dan derajat keasaman $(\mathrm{pH})$. Data yang diperoleh kemudian akan dibandingkan dengan kriteria baku mutu PP No. 82 Tahun 2001 untuk air kelas IV yang diperuntukan sebagai air untuk pertanaman pertanian atau irigasi.

\section{HASIL DAN PEMBAHASAN}

Kualitas air untuk pertanian adalah kesesuaian air untuk memenuhi fungsinya bagi tanaman, karena kualitas air yang baik tidak akan menganggu pertumbuhan tanaman dan hasil panen. Semakin buruk kualitas air, maka semakin berat permasalahan yang ditimbulkan serta penanganan yang dibutuhkan akan semakin sulit.

Hasil pengamatan dan pengukuran beberapa sifat fisik air irigasi yang meliputi Daya Hantar Listrik (DHL), Total Dissolved Solid (TDS) dan $\mathrm{pH}$ pada lahan sawah sekitar Sungai Suwatu disajikan pada Tabel 3, untuk selanjutnya diidentifikasi menggunakan kriteria mutu air berdasarkan kelas IV (PP No. 82 Tahun 2001) untuk TDS dan pH. Sedangkan untuk parameter DHL diidentifikasi menggunakan klasifikasi air irigasi berdasarkan DHL seperti pada Tabel 1 diatas.

Tabel 3.

Hasil Pengukuran Kualitas Air Irigasi pada Sawah Sekitar Sungai Suwatu

\begin{tabular}{ccccccc}
\hline \multirow{2}{*}{ Lokasi } & \multicolumn{2}{c}{ DHL $(\boldsymbol{\mu m h o s} / \mathbf{c m})$} & \multicolumn{2}{c}{ TDS $(\mathbf{m g} / \mathbf{l})$} & \multicolumn{2}{c}{ pH } \\
\cline { 2 - 7 } & Hasil Uji & BM & Hasil Uji & BM & Hasil Uji & BM \\
\hline A & 237,50 & Sangat Baik & 152 & Memenuhi & 7,7 & Memenuhi \\
B & 612,50 & Baik & 392 & Memenuhi & 5,1 & Tidak Memenuhi \\
C & 248,44 & Sangat Baik & 159 & Memenuhi & 7,5 & Memenuhi \\
D & 464,06 & Baik & 297 & Memenuhi & 5,6 & Tidak Memenuhi \\
\hline
\end{tabular}

Sumber: Hasil Pengujian (2013)

Daya hantar listrik sangat erat kaitannya dengan nilai salinitas suatu perairan. Semakin tinggi nilai salinitas suatu perairan makan semakin tinggi pula nilai DHL karena banyaknya garam-garam terlarut yang dapat terionisasi. Kualitas air irigasi perlu dijaga agar salinitasnya rendah, karena air dengan salinitas tinggi menyebabkan ujung daun kering dan menurunkan jumlah produksi tanaman tersebut (Susila dan Perwanto, 2013). Berdasarkan Tabel 3 diketahui bahwa nilai DHL pada air irigasi sawah sekitar Sungai Suwatu memenuhi persyaratan yang ditetapkan yaitu tergolong Sangat Baik
(<250 $\mu$ mhos/cm) untuk lokasi A dan C, serta Baik (>250 - $750 \mu \mathrm{mhos} / \mathrm{cm})$ untuk lokasi B dan D.

TDS merupakan salah satu parameter yang penting dalam air irigasi, TDS sangat mempengaruhi kualitas air irigasi karena mampu mempengaruhi tekstur, permeabilitas serta kesuburan tanah yang dilaluinya (Kurniati, 2009). Kandungan TDS pada air irigasi di sawah sekitar Sungai Suwatu masih memenuhi kualitas yang dipersyaratkan menurut PP No. 82 Tahun 2001 yaitu di bawah 2000 $\mathrm{mg} / \mathrm{l}$, seperti yang telah diperlihatkan pada Tabel 3. 


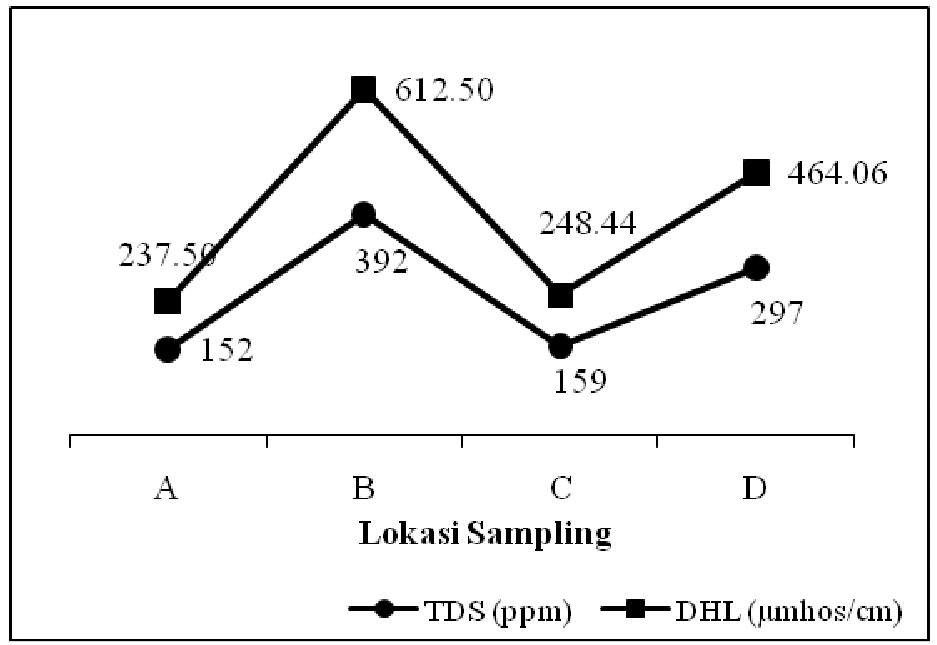

Gambar 1.

Grafik Hasil Pengukuran TDS dan DHL

Nilai DHL pada suatu perairan erat kaitannya dengan kandungan TDS pada perairan tersebut (Gambar 1). Hal ini bisa dilihat dari kandungan TDS pada lokasi A sebesar 152 mg/l dengan nilai DHL 237,50 $\mu \mathrm{mhos} / \mathrm{cm}$ yang kemudian meningkat pada lokasi B sebesar $392 \mathrm{mg} / \mathrm{l}$ yang juga diikuti dengan peningkatan nilai DHL menjadi $612,50 \mu \mathrm{mhos} / \mathrm{cm}$. Demikian pula dengan lokasi C dan D, dimana nilai DHL akan semakin meningkat seiring dengan peningkatan kandungan TDS pada air irigasi tersebut. Penelitian Desiandi dkk
(2010) menyatakan hal yang serupa bahwa semakin tinggi kadar TDS maka semakin tinggi pula nilai DHL pada perairan tersebut. Menurut Effendi (2003), TDS biasanya disebabkan oleh bahan anorganik yang berupa ion-ion yang biasa ditemukan di perairan dimana jumlah ion atau garam yang terlarut dalam air akan sangat mempengaruhi kemampuan air sebagai penghantar listrik. Oleh karena itu, semakin banyaknya ion pada suatu perairan maka nilai DHL akan semakin besar pada perairan tersebut.

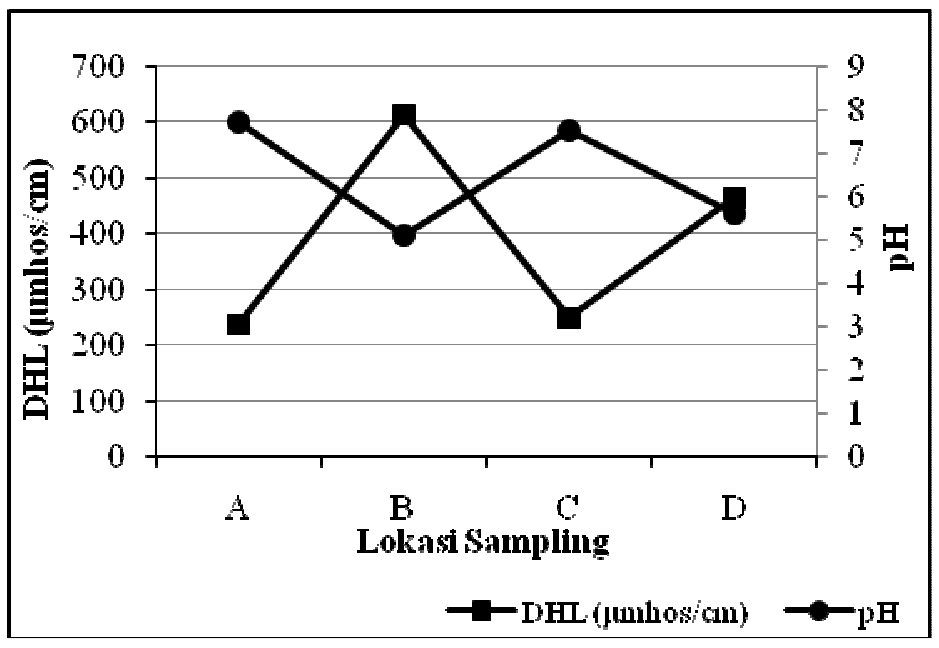

Gambar 2.

Grafik Hasil Pengukuran DHL dan pH 
Pada Tabel 3 diketahui bahwa tingginya $\mathrm{pH}$ akan diikuti dengan rendahnya nilai DHL, seperti pada lokasi sampling A dengan $\mathrm{pH}$ 7,7 dan DHL 237, $50 \mu \mathrm{mhos} / \mathrm{cm}$, yang kemudian mengalami penurunan $\mathrm{pH}(5,1)$ dan peningkatan $\mathrm{DHL}$ $(612,50 \mu \mathrm{mhos} / \mathrm{cm})$ pada lokasi sampling B. Hal serupa terjadi pada lokasi sampling C dan D, dimana nilai DHL akan menurun seiring dengan peningkatan nilai $\mathrm{pH}$ dan sebaliknya.

Hubungan DHL dan $\mathrm{pH}$ pada penelitian ini disajikan pada gambar 2 yang mendeskripsikan bahwa semakin kecil $\mathrm{pH}$ maka akan semakin besar nilai DHL pada perairan tersebut. Hal yang sama dinyatakan oleh Purnomo (2010) pada penelitiannya yang menyatakan bahwa semakin kecil nilai $\mathrm{pH}$ maka konduktivitas listrik perairan tersebut akan semakin besar dan sebaliknya. Pada konduktor elektrolit, elektron mengalir dibawa oleh ion-ion, sedangkan yang dapat menghasilkan ion antara lain asam, basa dan garam. Asam terdiri asam kuat yang banyak menghasilkan banyak ion sedangkan asam lemah menghasilkan sedikit ion dimana semakin asam suatu perairan maka semakin kecil nilai pHnya, demikian pula semakin lemah tingkat keasaman suatu perairan maka $\mathrm{pH}$ akan semakin besar. Sehingga apabila suatu perairan memiliki tingkat keasaman tinggi ( $\mathrm{pH}$ kecil) maka semakin banyak ion yang dihasilkan sehingga konduktivitas (DHL) akan semakin besar.

\section{KESIMPULAN DAN SARAN}

\section{Kesimpulan}

Secara umum, hasil pengujian DHL dan TDS pada 4 (empat) lokasi sampling masih memenuhi baku mutu yang dipersyaratkan menurut klasifikasi DHL (Tabel 1) dan PP No. 82 Tahun 2001 untuk air kelas IV. Sedangkan untuk parameter $\mathrm{pH}$, terdapat 2 (dua) lokasi sampling yang memiliki $\mathrm{pH}$ di bawah baku mutu yang dipersyaratkan yaitu lokasi sampling B dan
D dengan $\mathrm{pH}$ masing-masing 5,1 dan 5,6. Parameter DHL, TDS dan $\mathrm{pH}$ mempunyai hubungan yang saling terkait satu sama lain dimana nilai atau kandungan salah satu parameter akan sangat mempengaruhi nilai atau kandungan parameter lain.

\section{Saran}

Dengan mempertimbangkan hasil penelitian yang menyatakan bahwa parameter $\mathrm{pH}$ pada lokasi $\mathrm{B}$ dan $\mathrm{D}$ tidak memenuhi baku mutu, maka sebaiknya lokasi $\mathrm{B}$ dan $\mathrm{D}$ menggunakan air irigasi yang berasal dari campuran air tanah dan air Sungai Suwatu. Hal ini dimaksudkan untuk menaikkan nilai $\mathrm{pH}$ pada air irigasi tersebut. Untuk Dinas Kelautan Perikanan, Badan Lingkungan Hidup dan dinas terkait perlu melakukan pemantauan rutin terhadap kualitas air sungai dan kualitas air irigasi pada areal persawahan di sekitar Sungai Suwatu.

\section{DAFTAR PUSTAKA}

Astuti, D. A. 2012. Status Mutu Air Sungai Suwatu di Kecamatan Margoyoso Kabupaten Pati. Jurnal Litbang 8(2): 110-116.

Astuti, D. A. dan H. O. Damayanti. 2012. Analisis Kualitas Air dan Beban Pencemaran Air Limbah Tapioka (Studi Kasus di Sungai Suwatu, Margoyoso). Laporan Penelitian. Kantor Penelitian dan Pengembangan Kabupaten Pati. Pati.

Azwir. 2006. Analisa Pencemaran Air Sungai Tapung Kiri oleh Limbah Industri Kelapa Sawit PT. Peputra Masterindo di Kabupaten Kampar. Tesis. Program Studi Magister Ilmu Lingkungan Program Pasca Sarjana. Semarang : Universitas Diponegoro.

Bulumanis Kidul. 2012. Monografi Desa Bulumanis Kidul. Pati.

Desiandi, M., R. J. Sitorus. dan H. Hasyim. 2010. Pemeriksaan Kualitas Air 
Minum pada Daerah Persiapan Zona Air Minum Prima (ZAMP) PDAM Tirta Musi Palembang. Jurnal Ilmu Kesehatan Masyarakat 1(1): 67-72.

Effendi, H. 2003. Telaah Kualitas Air Bagi Pengelolaan Sumberdaya dan Lingkungan Perairan. Yogyakarta : Kanisius.

Fitriyah, A. 2012. Dampak Limbah Cair Pabrik Gula dan Pabrik Spiritus (PGPS) Madukismo Terhadap Produktivitas Padi di Desa Tirtonirmolo Kecamatan Kasihan Kabupaten Bantul. Skripsi. Program Stusi Pendidikan Geografi. Fakultas Ilmu Sosial. Yogyakarta : Universitas Negeri Yogyakarata.

Kurnati, E. 2009. Kualitas Air. Bahan Ajar Dasar Irigasi dan Drainase. Jurusan Keteknikan Pertanian. Fakutas Teknologi Pertanian. Malang : Universitas Brawijaya.

Peraturan Pemerintah Republik Indonesia Nomor 82 Tahun 2001 Tentang Pengelolaan Kualitas Air dan Pengendalian Pencemaran Air.

Poniman. 2004. Penanggulangan Pencemaran Limbah Cair Tapioka Pada Lahan Sawah. Laporan Penelitian. Pati : Balai Penelitian Lingkungan Pertanian.

Purnomo, H. 2010. Pengaruh Keasaman Buah Jeruk Terhadap Konduktivitas Listrik. Jurnal Orbith 6(2): 276-281.
Subagyono, K., A. Dariah. dan E. Surmaini., U. Kurnia. 2004. Tanah Sawah dan Teknologi Pengelolaannya. Badan Penelitian dan Pengembangan - Departemen Pertanian. Bogor : Pusat Penelitian dan Pengembangan Tanah dan Agroklimat.

Noordwijk. M. V. dkk. 2004. Peranan Agroforestri dalam Mempertahankan Fungsi Hidrologi Daerah Aliran Sungai (DAS). Jurnal Agrivita 26(1): 1-8.

Susila, A. D. dan R. Poerwanto. 2013. Irigasi dan Fertigasi. Modul IX Bahan Ajar Mata Kuliah DasarDasar Hortikultura. Bogor : Institut Pertanian Bogor.

Setiadi, R. 2011. Pengukuran Beberapa Unsur Mutu Air Irigasi. Laporan Resmi Praktikum Pengelolaan dan Kualita Air. Jurusan Teknik Pertanian, Fakultas Teknologi Pertanian. Yogyakarta : Institut Pertanian Stiper.

\section{BIODATA PENULIS}

Arieyanti Dwi Astuti, lahir 24 Agustus 1984 di kota Pati Jawa Tengah. Sarjana (S1) dari Universitas Diponegoro (UNDIP) Semarang Jurusan Teknik Lingkungan Tahun 2007. Saat ini bekerja sebagai peneliti di Kantor Penelitian dan Pengembangan Kabupaten Pati. 